\title{
Essential Classification
}

Vanda Broughton, Facet Publishing, UK, 2004, x 324 pages, ISBN 1-85604-514-5, £24.95 (paperback)

\section{George Macgregor}

\author{
Centre for Digital Library Research \\ University of Strathclyde
}

Facet Publishing, the successful publishing wing of the UK Chartered Institute of Library and Information Professionals, were smart to plug the glaring gap in novice level LIS publications and handbooks. Until Facet launched 'Essential Cataloguing', for instance, (reviewed by Stephen Winch in Vol.54, No.1), the best course of action for an LIS student, novice cataloguer or the practitioner who never received 'cat \& class', was to assume the brace position and hope the perceived flood of cryptic principles and conventions associated with MARC21 and AACR2 would simply disappear. Thankfully, Essential Cataloguing reversed this sorry scenario and has since become one of Facet's most successful publications of 2004 (Facet Publishing Online, 2005); appealingly accessible to the novice and useful for the dynamic practitioner.

Essential Classification represents a further addition to the Essential series and, like Essential Cataloguing, seeks to enlighten the novice in an accessible manner and demonstrate the applicability of traditional library concepts, especially within our chaotic quasi-global-digital-networked-information environment. Author Vanda Broughton begins by ushering the novice reader through a comprehensive introduction to classification; describing the need for, the principles, the varieties, the types, and the ordering within, classification schemes. This is closely followed by two chapters devoted entirely to ascertaining and describing the subject content of information entities and the practical constraints commonly encountered therein. Valuable chapters on controlled indexing languages and word-based approaches to subject based item retrieval (subject heading lists, thesauri, synonymy, etc.) are also provided and serve to gently ease the reader into what many would consider to be the very crux of classification: the classification schemes themselves.

Thus, from chapter twelve onwards, Broughton focuses on Library of Congress Classification (LCC), Dewey Decimal Classification (DCC), Universal Decimal Classification (UDC) and faceted classification, with complimentary chapters detailing the use of auxiliary tables, the peculiar characteristics of each scheme, and the practical application of such schemes using bona fide documents. Although somewhat hidden, Ranganathan's facet analysis and the Bliss Bibliographic Classification second edition (BC2) are collocated and elucidated within faceted classification chapter (Chapter 20). As well as peppering each chapter with 'real life' examples, Broughton simplifies complex and often abstract concepts with diagrammatical representations of classificatory principles and annotated worked examples, utilising snippets gathered from classification schedules. Should the novice remain bemused and falter, the admirable demystification process continues with chapter and 
section summaries, each providing bullet-point synopsises of what readers should take away from each section, as well as practical exercises. Practice, in this case, certainly makes perfect.

Perhaps more interestingly, Broughton reflects current global cataloguing trends - as well as the use of LCSH within distributed systems for ensuring semantic interoperability - by including a further two chapters on the use and application of basic and structured Library of Congress Subject Headings (LCSH). Given the ubiquitous nature of $\mathrm{LCSH}$, such an addition represents a veritable boon for the novice and presents Essential Classification as an excellent companion to Essential Cataloguing.

As a lecturer at the School of Library, Archive and Information Studies, based at University College London, Broughton has clearly honed her accessible and welcoming approach. Assuming the brace position is unlikely to be the typical reaction from those LIS students confronted with the intricacies of analytico-synthetic schemes, such as UDC, or the lengthy enumerative schedules of LCC. Broughton's accessible style is attributable, in part, to her extensive experience also; she is joint editor of the new edition of $\mathrm{BC}$, is a member of the UDC revision working group, and is also an avid member of the UK Classification Research Group. This wealth of experience allows her to assume an invisible intermediary role. By ensuring that the beginners are not overwhelmed by theory, schedules and tables, Broughton renders any eventual exposure more palatable for all. And this book is indeed for all. Essential Classification might be optimised for the LIS student or novice practitioner, but others engaging with classification and subject indexing are likely to find this book an invaluable working tool. It is, as the title suggests, essential.

\section{References}

Facet Publishing Online. (2005), Top 10 Books in 2004, CILIP, London. Available: http://www.facetpublishing.co.uk/top10.shtml (Accessed 13 May 2005) 